\title{
CORRIGENDUM
}

\section{Polymorphism in SNAP29 gene promoter region associated with schizophrenia}

T Saito, F Guan, DF Papolos, N Rajouria, CSJ Fann and HM Lachman. Mol Psychiatry 2001; 6: 193-201

Since the publication of the above paper, the authors have identified an error. The polymorphism designated $-849 \mathrm{~A} \rightarrow \mathrm{G}$ was erroneously named using the transcrip- tion start site as the point of reference rather than the translation start site. The correct designation should be $-923 A \rightarrow G$. 